\title{
A novel mitochondrial DNA deletion in a patient with Kearns-Sayre syndrome: a late-onset of the fatal cardiac conduction deficit and cardiomyopathy accompanying long-term rGH treatment
}

\author{
Monika Obara-Moszynska ${ }^{1 *}$, Jaroslaw Maceluch¹, Waldemar Bobkowski², Artur Baszko ${ }^{3}$, Oskar Jaremba², \\ Maciej R Krawczynski ${ }^{4}$ and Marek Niedziela ${ }^{1}$
}

\begin{abstract}
Background: Kearns-Sayre Syndrome (KSS) is a multisystem disorder caused by a dysfunction of the oxidative phosphorylation system within mitochondria. Mitochondrial DNA (mtDNA) rearrangements are a key molecular feature of this disease, which manifest a broad phenotypic spectrum.

Case presentation: Here, we present a boy with KSS whose symptoms included cardiac conduction deficit, cardiomyopathy and growth hormone (GH) deficiency. The patient showed typical symptoms for KSS from early childhood (chronic progressive external ophthalmoplegia, retinopathy, short stature). Long-range PCR analysis disclosed a 7663-base pair heteroplasmic deletion in the mtDNA encompassing nucleotides 6340-14003. At 12 years of age, GH deficiency was recognized and recombinant growth hormone $(\mathrm{rGH})$ therapy was started. At 15 years of age, a complete atrioventicular block was diagnosed and the patient received a pacemaker. During the following 6 months, progressive deterioration of the left ventricle was observed and an echocardiogram showed features of dilated cardiomyopathy. The rGH treatment was then discontinued at a final height of $163 \mathrm{~cm}$. Unfortunately, due to multi-organ insufficiency and inflammation, the patient died at the age of 18 years.

Conclusions: The response to $\mathrm{rGH}$ therapy in the patient was very satisfactory. The large mtDNA deletion had no apparent impact on the response to $\mathrm{rGH}$. Cardiac disturbances occurred as part of the syndrome and were not related to rGH therapy; however, the progression of the disease led to death.
\end{abstract}

Keywords: Growth hormone treatment, Mitochondrial disease, Atrio-ventricular block, Cardiomyopathy, Short stature

\section{Background}

Kearns-Sayre Syndrome (KSS) is a rare metabolic disorder which belongs to the group of mitochondrial cytopathies [1]. The diagnosis of KSS is made based on the classic triad of symptoms: onset of the disease before 20 years of age, progressive external ophthalmoplegia (PEO) and pigmentary retinopathy (PR) [2]. KSS is

\footnotetext{
* Correspondence: m.moszynska@ump.edu.pl

1 Department of Pediatric Endocrinology and Rheumatology, Poznan

University of Medical Sciences, 27/33 Szpitalna Street, 60-572, Poznan, Poland Full list of author information is available at the end of the article
}

manifested also by other systemic abnormalities: cardiac conduction defects, different neurological abnormalities and several endocrine disorders [3]. Progression of the clinical symptoms in KSS usually lead to death before the age of 30. Spontaneous mitochondrial DNA (mtDNA) rearrangements underlie this disease. A variety of deletions and/or duplications in mtDNA, affecting genes encoding respiratory chain proteins, are found in most cases [4-6]. This leads to defects in energy production by mitochondria and dysfunction of many tissues. This is particularly noticeable in tissues with a high energy demand - like 
muscles and the brain. The mutated mtDNA coexists with normal molecules (heteroplasmy) and the proportion of mutated to normal mtDNA correlates with the severity of clinical symptoms. There is no effective treatment for KSS and the complicated character of clinical features can impede the establishment of the correct diagnosis [1].

In this report we present the comprehensive clinical diagnosis of KSS in a young male. The patient was initially hospitalized based on neurological symptoms, followed by a diagnosis of his endocrinopathies. The most serious features of the disease - a cardiac conduction deficit and cardiomyopathy developed some years later. The final diagnosis was made several years after the first symptoms appeared, and was established using molecular biology techniques.

\section{Case presentation}

The presented patient is an 18-year-old boy with Kearns-Sayre Syndrome coexisting with GH deficiency, complicated by a cardiac conduction deficit and cardiomyopathy.

The child was adopted in early childhood and the family history is unknown. The delivery was at term and uncomplicated. The boy was born small for gestational age with a birth weight of $2500 \mathrm{~g}(-2,43 \mathrm{SD})$ and Apgar score of 10 points. From the second year of life, chronic progressive external ophthalmoplegia (CPEO) was observed. It started with unilateral ptosis (left eye), which gradually progressed to bilateral at 11 years of age. Additionally, extra-ocular muscle palsy and pigmentary retinopathy (PR) were observed. From early childhood, the boy displayed short stature by relative normal body weight (Figure 1, Figure 2).

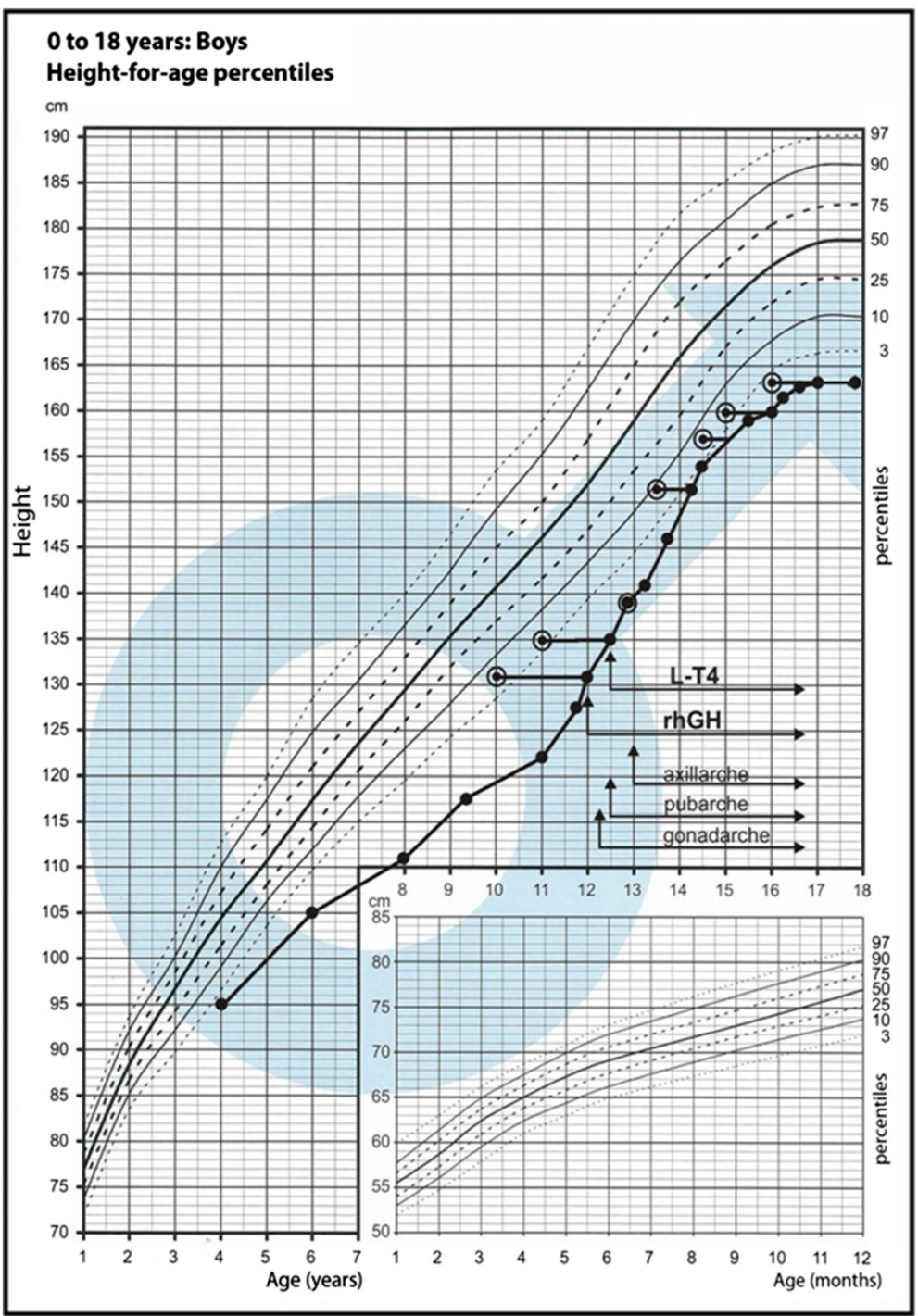

Figure 1 Growth chart with patient growth pattern. 


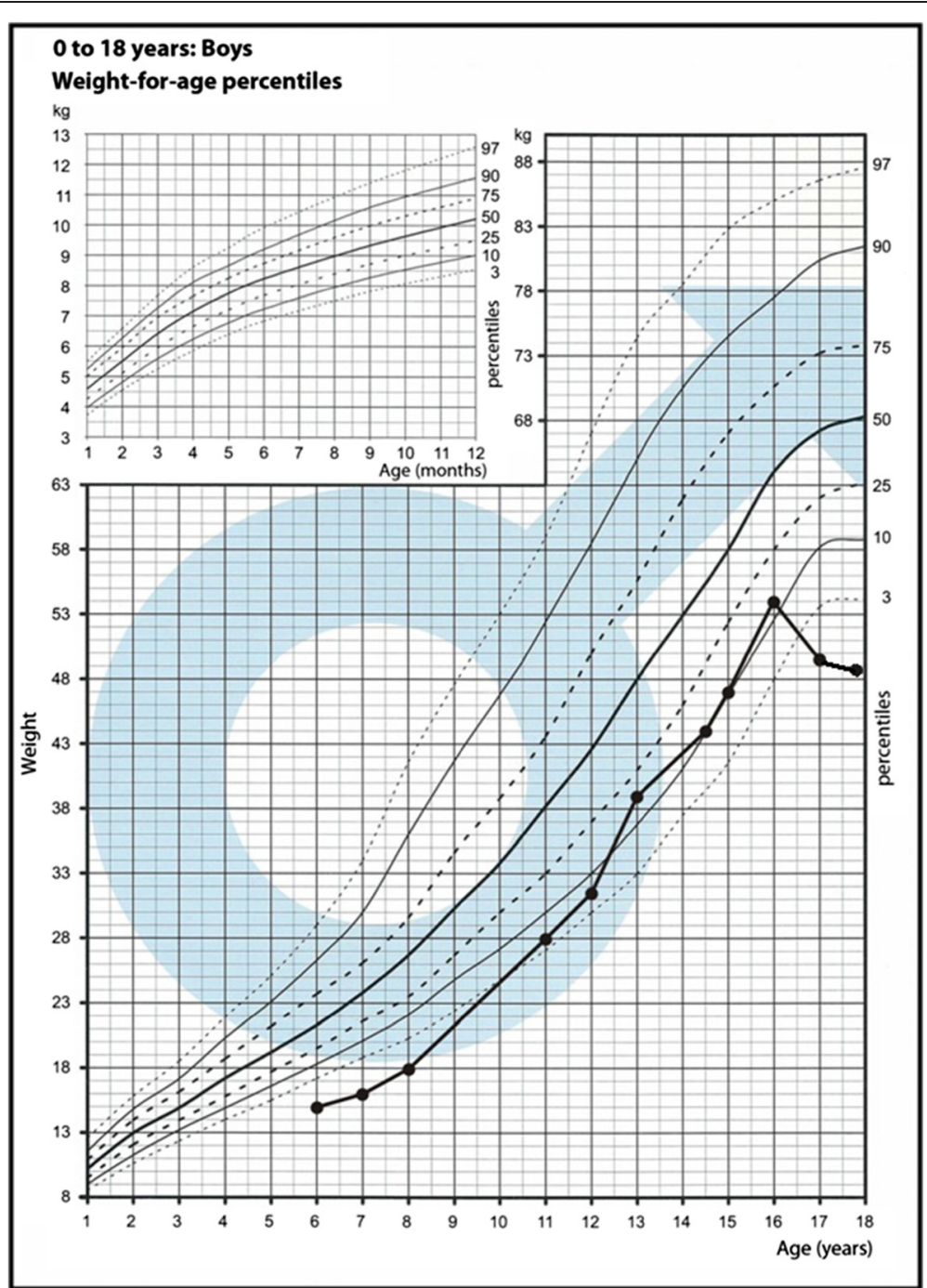

Figure 2 Growth chart with patient weight pattern.

Table 1 Selected parameters during rGH therapy

\begin{tabular}{|c|c|c|c|c|c|c|}
\hline & $\begin{array}{l}\text { Age } \\
\text { [years] }\end{array}$ & $\begin{array}{l}\text { Height } \\
\text { SDS }\end{array}$ & $\begin{array}{l}\text { Bone age [G\&P] } \\
\text { [years] }\end{array}$ & $\begin{array}{l}\text { Height velocity } \\
\text { [cm/year] }\end{array}$ & $\begin{array}{l}\text { Predicted adult height based on } \\
\text { Bayley-Pinneau method }[\mathrm{cm}]\end{array}$ & $\begin{array}{l}\text { rGH Dose } \\
{[\mathrm{mg} / \mathrm{kg} / 24 \mathrm{~h}]}\end{array}$ \\
\hline $\begin{array}{l}\text { the beginning of rGH } \\
\text { therapy }\end{array}$ & 12 & -3.5 & 10 & 8.5 & 161.9 & 0.024 \\
\hline $\begin{array}{l}\text { after } 6 \text { months of rGH } \\
\text { therapy }\end{array}$ & $126 / 12$ & -2.9 & 11 & 10.5 & 164.6 & 0.024 \\
\hline $\begin{array}{l}\text { after } 12 \text { months of rGH } \\
\text { therapy }\end{array}$ & 13 & -2.6 & 13 & 7.5 & 161.7 & 0.024 \\
\hline $\begin{array}{l}\text { after } 2 \text { years of } \mathrm{rGH} \\
\text { therapy }\end{array}$ & $143 / 12$ & -2.2 & $136 / 12$ & 10.0 & 168.5 & 0.022 \\
\hline $\begin{array}{l}\text { after } 3 \text { years of } \mathrm{rGH} \\
\text { therapy }\end{array}$ & $152 / 12$ & -2.3 & $146 / 12$ & 4.5 & 168.5 & 0.018 \\
\hline $\begin{array}{l}\text { after } 4 \text { years of } \mathrm{rGH} \\
\text { therapy }\end{array}$ & 16 & -2.3 & 15 & 2.5 & 166.5 & 0.018 \\
\hline $\begin{array}{l}\text { after } 5 \text { years of } \mathrm{rGH} \\
\text { therapy }\end{array}$ & 17 & -2.6 & 16 & 1.3 & 166 & $\begin{array}{l}\text { Discontinuation of } \\
\text { treatment }\end{array}$ \\
\hline
\end{tabular}


At the age of 11, he was admitted to the neurology clinic. An electromyogram (EMG) was performed and revealed a myogenic pattern. A magnetic resonance imaging (MRI) of the head showed hypoplasia of the pituitary gland. Examination of cerebrospinal fluid, auditory evoked potentials of the brainstem and electroencephalogram (EEG) were all normal. Psychological examination identified an IQ at average level. The genetic analysis showed a normal male $(46, \mathrm{XY})$ karyotype.

Due to the clinical picture (CPEO, PR) and EMG examination the diagnosis of Kearns-Sayre Syndrome (KSS) was proposed.

Further endocrine work-up detected a partial growth hormone deficiency. At 12 years of age, recombinant growth hormone (rGH) therapy was started with a standard dose $0.025 \mathrm{mg} / \mathrm{kg} /$ day (Table 1). During rGH treatment, the patient developed secondary hypothyroidism.
The onset of puberty was spontaneous and initiated at 12 years and 3 months of age.

HbA1c levels were borderline when rGH treatment was started and also 2 years later- they were $5.9 \%$ and $6.0 \%$ respectively (Table 2 ).

Further analysis revealed hyposecretion of insulin and an elevated blood glucose in oral glucose tolerance test (OGTT), glutamic acid decarboxylase (GAD), anti-insulin (IAA) and insulinoma antigen 2 (IA2) antibodies were all tested and were negative. Long acting insulin therapy was started and rGH dose was reduced. The glucose concentration then normalized. Insulin-like growth factor 1 (IGF1) levels during $\mathrm{rGH}$ administration were within the normal range, however, usually higher than the mean expected for age and sex. Levels of hormones and other biochemical parameters in blood samples are shown in Table 2.

Table 2 Levels of hormones and other biochemical parameters in blood samples (abnormal values are given in bold)

\begin{tabular}{|c|c|c|c|c|c|}
\hline \multirow[t]{2}{*}{ Laboratory tests } & \multirow[t]{2}{*}{10 yrs } & 12 & 14 & 16 & Reference range \\
\hline & & \multicolumn{4}{|c|}{ Results } \\
\hline TSH ( $\mu \mathrm{lU} / \mathrm{ml})$ & 2.1 & 2.99 & 0.44 & 0.36 & $0.470-4.640$ \\
\hline fT4 (ng/dl) & & 0.63 & 1.04 & 1.14 & $0.71-1.85$ \\
\hline ACTH $(p g / m l)$ & 31.7 & & & 30.7 & $10-60$ \\
\hline Cortisol (ng/ml) & & & & 143 & $94-260$ \\
\hline $\mathrm{LH}(\mathrm{mlU} / \mathrm{ml})$ & & & & 7.6 & $2.0-12.0$ \\
\hline FSH (mlU/ml) & & & & 6.3 & $1.0-8.0$ \\
\hline Testosterone (nmol/l) & & & & 19.83 & $8.84-26.1$ \\
\hline Prolactin (ng/ml) & & & & 7.09 & $3.24-29.12$ \\
\hline IGF-1 (ng/ml) & 212 & 428 & 511 & 602 & \\
\hline $\max \mathrm{GH}$ (after clonidine) (ng/ml) & 4.3 & & & & $>10$ \\
\hline max GH (after insulin) (ng/ml) & 1.5 & & & & $>10$ \\
\hline $\mathrm{HbA1c}(\%)$ & & 5.9 & 6.0 & 5.3 & $<6.1$ \\
\hline Glucose (mg/dl) & 91 & 88 & 84 & 79 & $59-101$ \\
\hline anti-GAD (U/ml) & & & 0.2 & 0.2 & $<1$ \\
\hline IAA (\%) & & & 4.3 & 5.4 & $<5.5$ \\
\hline $\mid \mathrm{A}-2(\mathrm{U} / \mathrm{ml})$ & & & 0.1 & & $<1$ \\
\hline $\mathrm{Na}^{+}(\mathrm{mmol} / \mathrm{l})$ & 139 & & 138 & 144 & $132-145$ \\
\hline $\mathrm{K}^{+}(\mathrm{mmol} / \mathrm{l})$ & 3.44 & & 3.39 & 4.97 & $3.1-5.1$ \\
\hline $\mathrm{Ca}(\mathrm{mmol} / \mathrm{l})$ & 2.55 & & 2.61 & 2.45 & $2.1-2.6$ \\
\hline $\mathrm{Mg}(\mathrm{mg} / \mathrm{l})$ & 17.2 & & 14.3 & 23.1 & $18.2-23.1$ \\
\hline$P(\mathrm{mg} / \mathrm{dl})$ & & & 4.52 & 4.63 & $4.50-5.52$ \\
\hline AspAt $(\mathrm{U} / \mathrm{l})$ & & & 25 & 23 & $1-40$ \\
\hline AlAt (U/I) & & & 20 & 23 & $1-45$ \\
\hline Creatinine (mg/dl) & & & 0.53 & 1.43 & $0.6-1.3$ \\
\hline Total protein (g/dl) & & & 7.6 & & $6.0-8.0$ \\
\hline $\lg A$ tTG & & & & neg & \\
\hline Cholesterol & & & 192 & 121 & $110-230$ \\
\hline
\end{tabular}


At 15 years of age, during a physical examination bradycardia was noticed. The patient displayed no major complaints concerning the cardiovascular system and his vital signs were all within normal limits - except for bradycardia. A detailed diagnostic work-up was ordered to determine the cause of the bradycardia. An electrocardiogram (ECG) examination was also performed and confirmed an intracardiac conduction abnormality characteristic of complete atrio-ventricular block with slow regular ventricular escape rhythm (rate of 35-38 bpm) with wide QRS complexes (Figure 3). The rate of the atrial rhythm was $80 \mathrm{bpm}$. As a next step, $24 \mathrm{~h}$ Holter monitoring was performed which confirmed the presence of a complete heart block, with minimum resting heart rate of $32 \mathrm{bpm}$, maximum of $49 \mathrm{bpm}$ and an average of $39 \mathrm{bpm}$. Echocardiogram examination was remarkable for mitral and tricuspid insufficiencies - both of second degree. The calculated shortening fraction was $36 \%$, with a left ventricular ejection fraction value of $65 \%$, good contractility was observed and the dimensions of the heart chambers were within normal limits. The next step performed was a surgical implantation of an artificial biventricular pacemaker under general anesthesia. The first active electrode was inserted through the basilic vein to the right ventricle and eventually placed in the septal part of right ventricular outflow tract, whereas the second active electrode was inserted through the subclavian vein and placed in the right atrium. The dualchamber pacemaker IDENTITY ADxXL DR from St. Jude Medical was successfully installed and programmed. Control electrocardiogram revealed a pacemaker rhythm of
$75 \mathrm{bpm}$ with ventricular stimulation controlled by the native sinus rhythm.

During the next 6 months, a progressive deterioration of the left ventricle was observed. In the performed echocardiogram, features of dilated cardiomyopathy were revealed. The picture of the heart suggested left ventricle noncompaction (LVNC), which is a congenital genetic developmental defect of heart muscle. At that time the boy had an implanted cardioverter - defibrillator with resynchronising stimulation. The prognosis was at that time also uncertain.

At the age of 17, the rGH therapy was discontinued due to a deceleration of height velocity - with a final obtained height of $163 \mathrm{~cm}$. Unfortunately, due to multiorgan insufficiency and inflammation, the patient died at the age of 18 years.

Molecular analysis of mitochondrial DNA was performed with total DNA isolated from the patient's peripheral blood. For molecular analysis, we obtained two separate blood samples collected at a two year interval. This allowed us to compare how genetic disturbances changed, if they did at all, with the progression of disease. $20 \mathrm{ng}$ of DNA was used for amplification of specific PCR products representing almost the whole mtDNA molecule (Figure 4A). Control reactions were performed using a DNA template from a healthy individual. Additional, smaller PCR products after gel electrophoresis were observed that indicated the presence of a deletion (Figure 4B). The analysis of sequences of the small product mapped the deletion to the region between nucleotides 6340 and 14003 on the

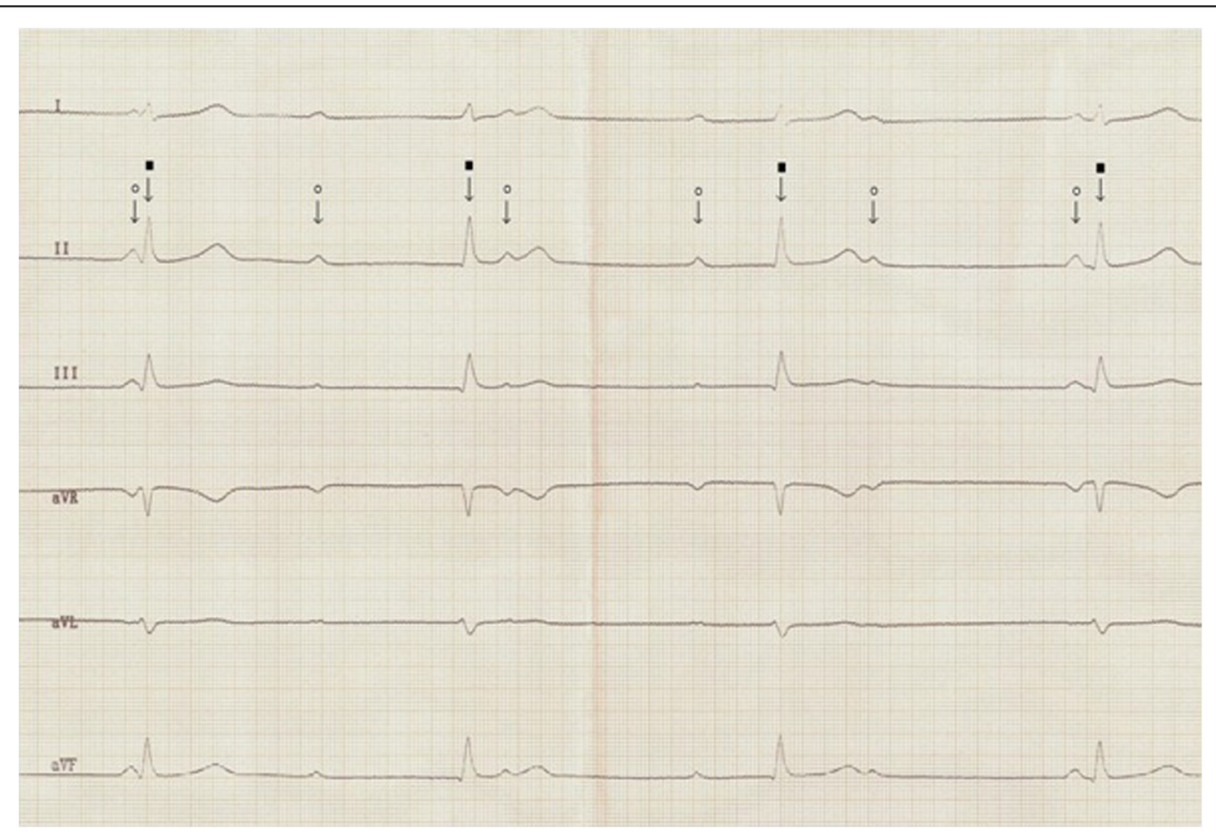

Figure 3 Standard ECG showing complete atrio-ventricular block. Atrial rhythm (white circle) of 70 bpm and ventricular escape rhythm of 42 bpm, narrow QRS (black square). Paper speed $50 \mathrm{~mm} / \mathrm{s}$. 


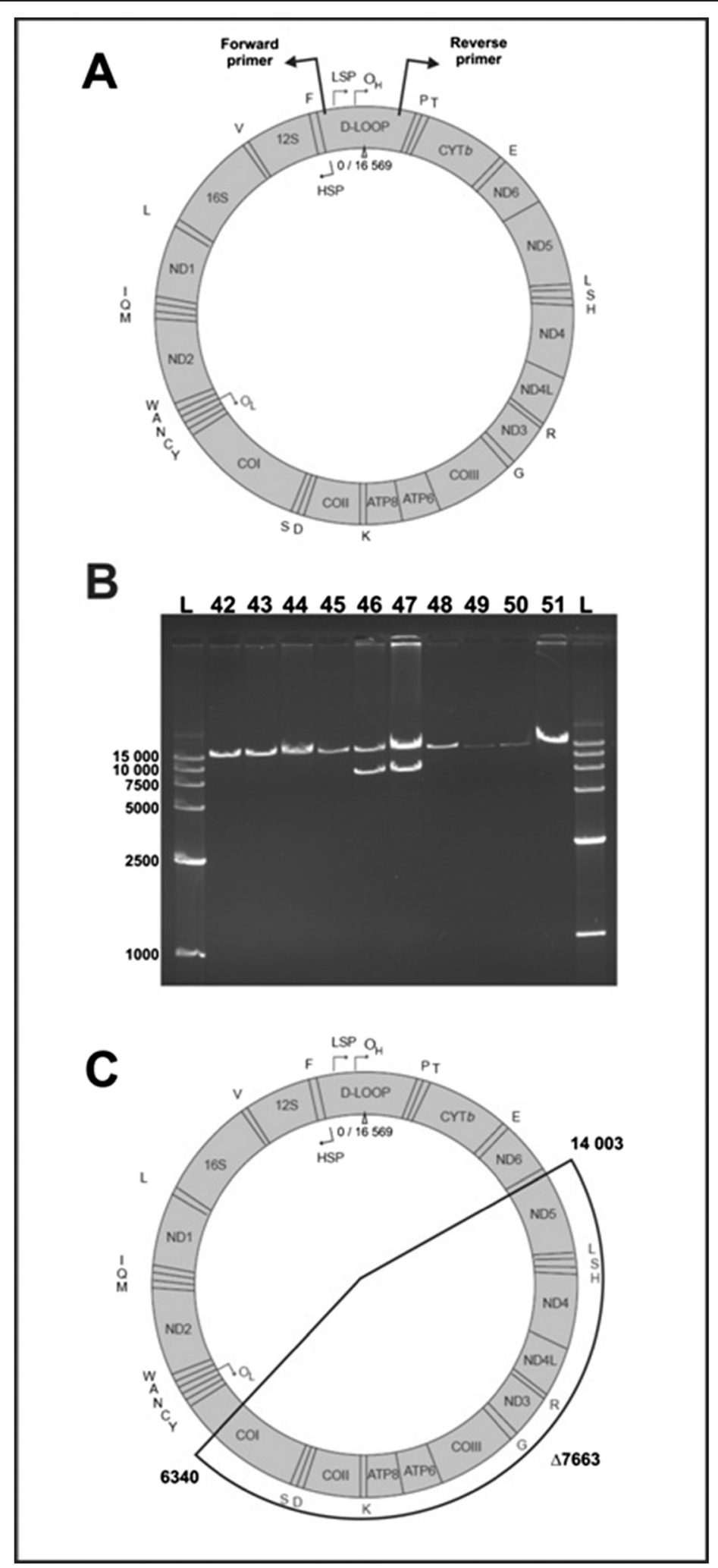

Figure 4 (See legend on next page.) 
(See figure on previous page.)

Figure $4 \mathbf{A}, \mathbf{B}, \mathbf{C}$. Results of molecular analysis of patient's mitochondrial DNA. A - Schematic localization of PCR primers used for the detection of deletion in mtDNA; $\mathbf{B}$ - Result of Long-Range PCR detection of mitochondrial deletion, numbers represent samples from different patients suspected for KSS, numbers 46 and 47 represent two samples from presented patient, L indicates molecular weight ladder (GelPilot High Range Ladder, QIAGEN); C - Schematic localization of detected mtDNA deletion.

mtDNA molecule (Figure 4C). This big deletion (7663 bp) removes almost half of the mtDNA molecule along with genes which encode critical proteins in the mitochondrial electron transport chain: cytochrome c oxydase, NADH dehydrogenase, ATP synthase and 8 tRNAs. Such a dramatic rearrangement of mitochondrial DNA must have a significant impact on mitochondrial function, but the influence of this deletion on clinical symptoms and the severity of the disease also depends on the level of heteroplasmy.

Quantitative analysis of the heteroplasmy level was performed by Real-Time PCR technique. $20 \mathrm{ng}$ of total DNA was analyzed using QuantiTect SYBR Green PCR Kit (Qiagen) on a Mastercycler ep realplex machine (Eppendorf) and four specially designed primer sets. All reactions were done in triplicate. Melting curve analysis was added at the end of all reactions. Relative expression ratios of mtDNA levels were calculated using the $\Delta C_{T}$ method. As a control of the total mtDNA level, we analyzed the DNA of five healthy individuals, using the same primers as for the patient. Amplification results were presented as a relative expression towards the expression level of a housekeeping, nuclear gene - GAPDH. The results of this analysis revealed that the total level of mtDNA in the patient's blood was comparable to the normal mtDNA level in the first, older DNA sample, but significantly higher $(2.6 \times)$ in the second sample.

Next, we tested the heteroplasmy level, analyzing in separate reactions only normal, non-deleted mtDNA molecules, or only molecules with the deletion. A comparison of the results of these two reactions revealed that mtDNA molecules with the deletion comprise about $3 \%$ of the total mtDNA pool in the patient's blood.

The presented patient is a case with a typical symptom sequence of KSS (Figure 5) and with a big, novel deletion in mtDNA.

This observation, with changing total mtDNA, fits well with the standard pattern of genetic rearrangements during the course of mitochondrial cytopathies. It was demonstrated that in patients with single deletions at high heteroplasmy levels the amount of mitochondria within the cells was nearly doubled [7]. Therefore, even considerably reduced levels of enzyme activity can be compensated for by increased amounts of mitochondria. In another investigation, an approximately nine-fold amplification of mtDNA in muscle was detected [8]. Other reports also

\section{Clinical disorders in the examined patient with KSS}

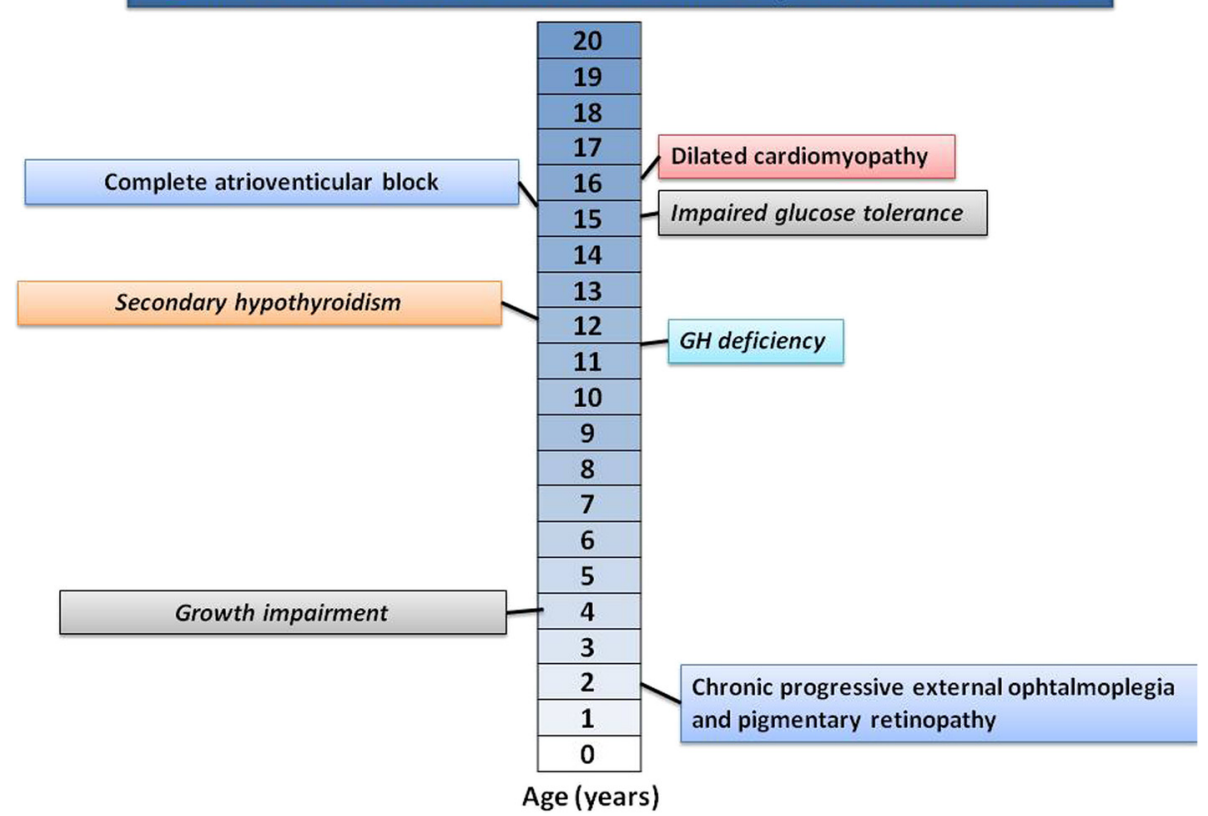

Figure 5 Chronologic occurrence of clinical symptoms in presented boy. 
indicate a synchronous increase in the levels of deleted and normal mtDNA in the course of KSS [9].

The low percentage of the deleted form of mtDNA compared to total mtDNA was not surprising, because the level of mutated mtDNA in blood is usually very low and sometimes undetectable [5]. The observed level of mutated mtDNA in blood lymphocytes does not correlate with the severity of observed clinical symptoms of the disease. It is also likely that the level of mutated mtDNA in other tissues was much higher, but that was impossible for us to test because we lacked a muscle biopsy specimen for analysis.

The boy had the classic triad, plus the cardiac conduction defect. The dominant disturbances at the beginning of disease manifestation were ophthalmologic, then endocrinologic. With the development of the disease, the cardiac complications became very severe, subsequently leading to a life-threatening state.

Most cases of KSS (like the presented patient) and other mitochondrial cytopathies are first diagnosed as various endocrine disorders and the diagnosis of KSS is later established after several years $[10,11]$.

Endocrinologic pathologies in the presented patient were as follows: GH deficiency, hypothyroidism and impaired endocrine function of the pancreas. At the beginning of rGH treatment the prognosis concerning the therapy response was uncertain. The improvement of height velocity during $\mathrm{rGH}$ therapy was very satisfactory, and exceptional if compared to other children treated with KSS in our clinic. After glucose metabolism became impaired and the dose of rGH was reduced, the patient still accelerated on his growth chart. This means that the growth signal was transduced properly, despite the main disease. The large mtDNA deletion and resultant metabolic defects had no impact on treatment response to $\mathrm{rGH}$.

The cardiac manifestations of KSS are the most important aspects of the disease for determining the prognosis [12]. Manifestations of cardiac disease occur in 57\% of patients with Kearns-Sayre Syndrome, including syncopal attacks, heart failure and cardiac arrest [13]. Patients with KSS typically develop cardiac conduction defects that progress to complete heart block and then manifest clinically as heart failure, syncope or sudden death. Cases described in the literature show the progressive course of lifethreatening conduction abnormalities in KSS [14]. Patients who do not have conduction disturbances should be closely monitored for the development of conduction defects. In all patients with mtDNA mutations, not just KSS patients, mortality among those with no cardiac disease is $26 \%$ vs. $71 \%$ in patients with cardiomyopathy [15]. Pacemakers are recommended for all patients with neuromuscular diseases (including KSS) who have developed atrioventricular (AV) block, however, prophylactic pacemaker placement prior to the development of third-degree or advanced second-degree AV block is discussed with patients and families as well [16]. Based on the International Society of Heart and Lung Transplantation database, 6 patients who received heart transplantation between 1990 and 2003 had a diagnosis of myopathy due to a mitochondrial pathology [17].

The question is whether rGH treatment could have an impact on the cardiological complications in the patient. $\mathrm{GH}$, both in excess and in deficient states can be associated with increased cardiovascular disturbances. Exposure to high $\mathrm{GH}$ levels causes the hypertrophy of cardiac myocyte [18]. Patients with GH oversecretion develop acromegalic cardiomyopathy, biventricular hypertrophy and eventual heart failure [19]. Dysrhythmias are also observed in acromegaly. Most common are ventricular arhythmias, like premature ventricular beats, ventricular bigeminy and ventricular tachycardia [20]. In $\mathrm{GH}$ deficiency an increased risk of ischemic heart disease is described [21]. GH deficiency results in a change in body composition, bone mineral density, an altered lipid profile, and decreased muscle mass. Therefore the proper balance within the GH and IGF-1 axis is necessary for maintaining normal cardiac function.

The presented patient had growth hormone deficiency and was treated with substitution doses of $\mathrm{rGH}$. The IGF-1 concentration during rGH administration was within the normal range throughout the entire period of treatment. Therefore, the proper homeostasis of GH and IGF-1 axis was maintained. There is no evidence that rGH could have had a negative impact on cardiac function in this boy. It is rather to be suspected that treatment with rGH could even have a beneficial influence on the heart. There are some studies that show a positive influence of rGH on myocardium, also in dilated cardiomyopathy. GH can improve left ventricle structure and cardiac output, leading to a better hemodynamic profile of the heart [22,23].

\section{Conclusions}

The presented case shows the classical clinical characteristics of Kearns-Sayre Syndrome. The urgent and rapid manifestation of severe cardiac dysfunction emphasizes the necessity of careful cardiological follow-up in KSS. The response to $\mathrm{rGH}$ in KSS is somewhat unpredictable, similarly to cardiac dysfunction, and there is no proof that rGH treatment contributes to the onset of the conduction block.

\section{Consent}

Written informed consent was obtained from the mother of the patient for publication of this case report and any accompanying images. A copy of the written consent is available for review by the Series Editor of this journal. 


\section{Abbreviations}

KSS: Kearns-Sayre Syndrome; mtDNA: Mitochondrial DNA; GH: Growth hormone; rGH: Recombinant growth hormone; PEO: Progressive external ophthalmoplegia; PR: Pigmentary retinopathy; CPEO: Chronic progressive external ophthalmoplegia; EMG: Electromyogram; MRI: Magnetic resonance imaging; EEG: Electroencephalogram; OGTT: Oral glucose tolerance test; GAD: Glutamic acid decarboxylase; IAA: Anti-insulin antibodies; IA2: Insulinoma antigen 2; IGF-1: Insulin-like growth factor 1; ECG: Electrocardiogram; PCR: Polymerase chain reaction.

\section{Competing interests}

None of the authors of the manuscript has declared any financial and nonfinancial competing interests in relation to this manuscript.

\section{Authors' contributions}

MO-M conceptualized and designed the study, drafted the initial manuscript and approved the final manuscript as submitted. JM was responsible for molecular analysis, drafted the initial manuscript, completed the molecular analysis in the manuscript and approved the final manuscript as submitted. WB was involved in the cardiologic care of the patient, coordinated and supervised the cardiologic part of the manuscript and approved the final manuscript as submitted. $A B$ was involved in the cardiologic care of the patient, approved the final manuscript as submitted. OJ was involved in the cardiologic care of the patient, was involved in the cardiologic part of the manuscript and approved the final manuscript as submitted. MRK was involved in the molecular part of the study, coordinated and supervised the genetic part of the manuscript, approved the final manuscript as submitted. MN conceptualized and designed the study, coordinated and supervised the study, drafted the initial manuscript and approved the final manuscript as submitted.

\section{Acknowledgements}

* Sections of this work were presented during the Joint Meeting of European Society for Paediatric Endocrinology and The Lawson Wilkins Pediatric Endocrine Society (ESPE/LWPES), $44^{\text {th }}$ Annual ESPE Meeting in Lyon (September 2005) and $50^{\text {th }}$ Annual ESPE Meeting in Glasgow (September 2011).

This work was supported by a grant from MNiSzW (2 P05A 070 30).

\section{Author details}

'Department of Pediatric Endocrinology and Rheumatology, Poznan University of Medical Sciences, 27/33 Szpitalna Street, 60-572, Poznan, Poland. ${ }^{2}$ Department of Pediatric Cardiology and Nephrology, Poznan University of Medical Sciences, Poznan, Poland. ${ }^{3}$ 2nd Department of Cardiology, Poznan University of Medical Sciences, Poznan, Poland. ${ }^{4}$ Department of Medical Genetics, Poznan University of Medical Sciences, Poznan, Poland.

Received: 20 August 2012 Accepted: 12 February 2013 Published: 20 February 2013

\section{References}

1. Maceluch JA, Niedziela M: The clinical diagnosis and molecular genetics of Kearns-Sayre syndrome: a complex mitochondrial encephalomyopathy. Pediatr Endocrinol Rev 2007, 4:117-137.

2. Berenbaum $F$, Cote $D$, Pradat $P$, Rancurel $G$ : Kearns-Sayre syndrome. Neurology 1990, 40:193-194.

3. Harvey JN, Barnett D: Endocrine dysfunction in Kearns-Sayre syndrome. Clin Endocrinol 1992, 37:97-103.

4. Moraes $C T$, DiMauro S, Zeviani M, Lombes A, Shanske S, Miranda AF, Nakase H, Bonilla E, Werneck LC, Servidei S, Nonaka I, Koga Y, Spiro AJ, Keith A, Brownell KW, Schmidt B, Schotland DL, Zupanc M, Fr-Vivo DC, Schon EA, Rowland LP: Mitochondrial DNA deletions in progressive external ophthalmoplegia and Kearns-Sayre syndrome. N Engl J Med 1989, 320:1293-1299.

5. Holt IJ, Harding AE, Morgan-Hughes JA: Deletions of mitochondrial DNA in patients with mitochondrial myopathies. Nature 1988, 331:717-719.

6. Poulton J, Deadman ME, Gardiner RM: Duplications of mitochondrial DNA in mitochondrial myopathy. Lancet 1989, 1:236-240.

7. Wallace DC, Lott MT, Torroni A, Brown MD, Shoffner JM: Report of the committee on human mitochondrial DNA. In Human gene mapping.
Edited by Cuticchia AJ, Pearson PL. Baltimore: Johns Hopkins University Press: 1994:813-845.

8. Nakase $H$, Moraes $C T$, Rizzuto $R$, Lombes $A$, DiMauro S, Schon EA: Transcription and translation of deleted mitochondrial genomes in Kearns-Sayre syndrome: implications for pathogenesis. Am J Hum Genet 1990, 46:418-427.

9. DiMauro S, Moraes CT, Shanske S, Lombes A, Nakase H, Mita S, Tritschler HJ, Bonilla E, Miranda AF, Schon EA: Mitochondrial encephalomyopathies: biochemical approach. Rev Neurol 1991, 147:443-449.

10. Burns EC, Preece MA, Cameron N, Tanner JM: Growth hormone deficiency in mitochondrial cytopathy. Acta Paediatr Scand 1982, 7:693-697.

11. Quade A, Zierz S, Klingmuller D: Endocrine abnormalities in mitochondrial myopathy with external ophthalmoplegia. Clin Invest 1992, 70:396-402

12. Chawla S, Coku J, Forbes T, Kannan S: Kearns-Sayre syndrome presenting as complete heart block. Pediatr Cardiol 2008, 29:659-662.

13. Berenberg RA, Pellock JM, DiMauro S, Schotland DL, Bonilla E, Eastwood A, Hays A, Vicale CT, Behrens M, Chutorian A, Rowland LP: Lumping or splitting? "Ophthalmoplegia-plus" or Kearns-Sayre syndrome? Ann Neurol 1977, 1:37-54.

14. Agrawal H, Ekhomu O, Choi HW, Naheed Z: Natural history of conduction abnormalities in a patient with Kearns-Sayre syndrome. Pediatr Cardiol 2012, [Epub ahead of print].

15. Bindoff $L:$ Mitochondria and the heart. Eur Heart J 2003, 24:221-224.

16. Epstein AE, Dimarco JP, Ellenbogen KA, Estes NA 3rd, Freedman RA, Gettes LS, Gillinov AM, Gregoratos G, Hammill SC, Hayes DL, Hlatky MA, Newby LK, Page RL, Schoenfeld MH, Silka MJ, Stevenson LW, Sweeney MO: American College of Cardiology/American heart association task force on practice, american association for thoracic surgery, society of thoracic surgeons: ACC / AHA / HRS 2008 guidelines for devicebased therapy of cardiac rhythm abnormalities:executive summary. Heart Rhythm 2008, 5:934-955.

17. Bhati RS, Sheridan BC, Mill MR, Selzman CH: Heart transplantation for progressive cardiomyopathy as a manifestation of MELAS syndrome. $J$ Heart Lung Transplant 2005, 24:2286-2289.

18. Reiss K, Kajstura J, Zhang X, Li P, Szoke E, Olivetti G, Anversa P: Acute myocardial infarction leads to upregulation of the IGF-1 autocrine system, DNA replication, and nuclear mitotic division in the remaining viable cardiac myocytes. Exp Cell Res 1994, 213:463-472.

19. Colao A: 5 long-term acromegaly and associated cardiovascular complications: a case-based review. Best Pract Res Clin Endocrinol Metab 2009, 23(suppl 1):S31-S38.

20. Rodrigues EA, Caruana MP, Lahiri A, Nabarro JD, Jacobs HS, Raftery EB: Subclinical cardiac dysfunction in acromegaly: evidence for a specific disease of heart muscle. Br Heart J 1989, 62:185-194.

21. Verhelst J, Abs R: Cardiovascular risk factors in hypopituitary GH-deficient adults. Eur J Endocrinol 2009, 161(suppl 1):S41-S49.

22. Genth-Zotz S, Zotz R, Geil S, Voigtländer T, Meyer J, Darius H: Recombinant growth hormone therapy in patients with ischemic cardiomyopathy: effects on hemodynamics, left ventricular function, and cardiopulmonary exercise capacity. Circulation 1999, 99:18-21.

23. Perrot $\mathrm{A}$, Ranke MB, Dietz R, Osterziel $\mathrm{KJ}$ : Growth hormone treatment in dilated cardiomyopathy. J Card Surg 2001, 16:127-131.

\section{doi:10.1186/1471-2431-13-27}

Cite this article as: Obara-Moszynska et al:: A novel mitochondrial DNA deletion in a patient with Kearns-Sayre syndrome: a late-onset of the fatal cardiac conduction deficit and cardiomyopathy accompanying long-term rGH treatment. BMC Pediatrics 2013 13:27. 